\title{
Sixth-grade students' reasoning on the order relation of integers as influenced by prior experience: an inferentialist analysis
}

\author{
Maike Schindler ${ }^{1}$ (D) Stephan Hußmann ${ }^{2}$. \\ Per Nilsson $^{1} \cdot$ Arthur Bakker $^{3}$
}

Received: 9 October 2016 / Revised: 1 March 2017 / Accepted: 5 March 2017 /

Published online: 23 March 2017

(C) The Author(s) 2017. This article is published with open access at Springerlink.com

\begin{abstract}
Negative numbers are among the first formalizations students encounter in their mathematics learning that clearly differ from out-of-school experiences. What has not sufficiently been addressed in previous research is the question of how students draw on their prior experiences when reasoning on negative numbers and how they infer from these experiences. This article presents results from an empirical study investigating sixth-grade students' reasoning and inferring from school-based and out-of-school experiences. In particular, it addresses the order relation, which deals with students' very first encounters with negative numbers. Here, students can reason in different ways, depending on the experiences they draw on. We study how students reason before a lesson series and how their reasoning is influenced through this lesson series where the number line and the context debts-and-assets are predominant. For grasping the reasoning's inferential and social nature and conducting in-depth analyses of two students' reasoning, we use an epistemological framework that is based on the philosophical theory of inferentialism. The results illustrate how the students infer their reasoning from out-of-school and from school-based experiences both before and after the lesson series. They reveal interesting phenomena not previously analyzed in the research on the order relation for integers.
\end{abstract}

Keywords Negative numbers · Negative integers · Reasoning · Prior experiences · Contexts · Inferentialism

Maike Schindler

maike.schindler@oru.se

1 School of Science and Technology, Örebro University, S-701 82 Örebro, Sweden

2 IEEM, TU Dortmund University, Dortmund, Germany

3 Freudenthal Institute, Utrecht University, Utrecht, Netherlands 


\section{Introduction}

Negative numbers are among the first formalizations students encounter in their mathematics learning that clearly differ from out-of-school experiences. ${ }^{1}$ Negative numbers and the mathematically correct order relation are hardly inferable from outof-school contexts for students; they are not representable with concrete objects that one could manipulate (Davidson 1987) and they are often perceived "fictive" (Vlassis 2004; cf. Tsang et al. 2015). Thus, getting to understand negative numbers can constitute challenges for students. Empirical studies revealed surprisingly low performances of certain students (e.g., Bruno and Cabrera 2005; Peled 1991) and an enormous heterogeneity in student performance (e.g., Bruno et al. 2001). Mukhopadhyay (1997, p. 35) summarized that "negative numbers are often viewed as unsolvable mysteries by many students"; Murray (1985, p. 152) speaks of "deeplyrooted and widely-held misconceptions" among students.

Research on negative numbers has so far largely focused on students' abilities to calculate (Pierson-Bishop et al. 2014a) and has revealed the difficulties students have when calculating with negative numbers (e.g., Gallardo 1995). Some of the studies focused as well on students' understanding of and reasoning on negative numbers (e.g., Bofferding 2014; Pierson-Bishop et al. 2014a, b; Widjaja et al. 2011); for instance, on students' mental models (e.g., Bofferding 2014; Peled et al. 1989), the metaphors they use when encountering negative numbers (Chiu 2001), cognitive obstacles and affordances (Pierson-Bishop et al. 2014b), and developmental milestones when getting to know negative numbers (Pierson-Bishop et al. 2014a).

Even though it is a common assumption among scholars in mathematics education that students' prior experiences are crucially important in knowledge development, the question of how students draw on prior experiences when comparing negative integers has rarely been studied. Recent research has predominantly addressed students' reasoning in representational terms, such as mental models (Bofferding 2014). However, students' reasoning on the order relation of integers is manifold (Pierson-Bishop et al. 2014b) and can hardly be conceived in its details via categorizing it in, for instance, two mental models. We think that investigating students' reasoning on the order relation for integers requires analytical approaches that cope with the variety and sophistication of students' reasoning from both school-based experiences and out-of-school experiences and its inferential linkage. We share with enactivist and sociocultural researchers the wish to focus on students' actual doing and on reasoning in particular rather than making assumptions about students' underlying internal or mental models (see also Roth 2016a).

The purpose of this paper is to investigate how students draw on school-based and out-of-school experiences when reasoning on the order relation for integers and how they infer from them. It presents a study in which students' reasoning on the order relation for integers is investigated on behalf of inferentialism, a philosophical background theory (Brandom 1994, 2000) that helps to grasp the inferential linkage in students' reasoning (e.g., Bakker and Derry 2011). Whereas many externalist

\footnotetext{
${ }^{1}$ We use the terms negative number and negative integer as synonyms in this paper because the introduction to negative numbers, which is addressed in this paper, focuses on negative integers; not on non-whole rational or irrational negative numbers.
} 
perspectives focus on doings, the particular power of inferentialism is its perspicuous view on meaning making through reasoning as a specific type of doing. Its focus on inference fits well with the needs within mathematics education research. In order to study how students use their experiences in school-based learning, we studied students' reasoning in interviews before and after a lesson series. The focus of the paper is not how effective learning in this series was, but rather it offers us a context in which we study the aforementioned question of how students make inferences from prior experience about the mathematical topic of negative numbers. This analysis yielded insight into interesting phenomena, at least of one which we had not seen analyzed in the literature before.

\section{Theoretical background}

\section{Students' reasoning on the order relation for integers}

The order relation for integers deals with students' initial formal introduction to negative numbers. It is one of the first topics students encounter in lesson series on negative numbers at school, which is basic for integer addition, subtraction, multiplication, and division. It is - in out-of-school contexts - understandable in another way than in mathematics (e.g., when the instruction on frozen food packages says it should be stored at at least $-18{ }^{\circ} \mathrm{C}$; or when a $15 \mathrm{k} €$ debt is a greater debt than a $8 \mathrm{k} € \mathrm{debt}$ ). Given the assumption that students draw on prior experiences when comparing and ordering integers, the question arises of what prior experiences students draw on and how they infer from them.

Mental models One of the initial investigations addressing the order relation of integers was conducted by Peled et al. (1989) who asked students in different grades to determine the greater between two numbers. They tried to explain student answers by postulating two mental models: the divided vs. continuous number line model. In simple words, the continuous number line model represents the idea of "the further right on the number line, the greater the number." In the divided number line model, the basic idea is "the further away from zero, the greater the number," leading to the incorrect assumption that, for instance, -6 is greater than -4 . However, the divided number line model often leads to correct answers, when students, for instance, compare -6 and 4 or state that a $40 €$ debt is less than a $60 €$ debt. It constitutes a "local bit of knowledge" (Sackur and Drouhard 1997) that serves rather far-and it is only through looking more deeply at students' reasoning that this model may get apparent. ${ }^{2}$ In a similar vein, Bofferding (2014) investigated first graders' mental models when encountering questions about negative integer values, order, and directed magnitudes. She found that students' understanding of negative numbers is "heavily constrained" ( $\mathrm{p}$. 229 ) by their prior experiences with whole numbers and principles that they had built previously, indicating that prior experiences can constitute an obstacle for students when reasoning on negative numbers. These results indicate that a focus on students' actual doings and reasoning - as stated in this paper - potentially offers the opportunity

\footnotetext{
${ }^{2}$ This will be illustrated in the data analysis presented in this paper.
} 
to get even deeper insights into students' challenges and struggles dealing with negative numbers and the order relation than an analysis drawing on mental models.

External representations Bruno and Cabrera (2005) investigated how students aged 13 and 14 changed representations when ordering integers. They found three kinds of strategies the students used: using the number line, paying attention to the negative signs in the formal-symbolic representation, and drawing on real-life contexts. This connects to Pierson-Bishop et al.'s (2014b) finding that a second grader took three different views on integers when reasoning on the order relation: an ordinal, a cardinal, and a formal-symbolic view. The researchers concluded that "students need each of these understandings to reason robustly about integers and that, at times, proficient students may draw on more than one view of number to reason about a single integer problem" (p. 41). In sum, the results from these studies (see also Bruno and Martinón 1996; Peled 1991; Malle 1988) indicate that students can take different perspectives when reasoning on the size of integers: predominantly a symbolical, contextual, and an ordinal perspective, whereas the shifts between the symbolic, contextual, and ordinal representations appear critical for students' reasoning on negative numbers, as "[c]hanging representation register is the threshold of mathematical comprehension for learners at each stage of the curriculum" (Duval 2006, p. 128) (Fig. 1). In particular, empirical research on real-life contexts and their role in integer learning has indicated the opportunities that real-life contexts hold for students' reasoning and understanding of integers (e.g., Borba 1995; Bruno 1997; Bruno and Martinón 1996; Stephan and Akyuz 2012). ${ }^{3}$ Mukhopadhyay et al. (1990) summarized their findings stating, "people show a superior ability to use and understand mathematical ideas when the relevant concepts and operations are introduced in a contextualized, familiar social situation" (p. 287). Real-life contexts give students the possibility to connect to familiar situations and infer their reasoning from them. Research on the ordinal representation of negative numbers and the number line has furthermore revealed that this representation can foster students' understanding of negative numbers, and it appears to be a successful model (Beatty 2010) and cognitive affordance (Pierson-Bishop et al. 2014a). Even though students' ability to use the number line for reasoning on negative numbers depends on students' prior experiences with the number line (Bruno 2001), after a lesson series where the number line was extensively used as a model, initial difficulties tend to disappear (Bruno and Martinón 1997).

\section{Theoretical framework: reasoning from an inferential perspective}

In this section, we present the background theory underlying our study, inferentialism. Background theories concern the theoretical foundations studies rely on and play a crucial role for "discerning and defining what kind of objects are to be studied" (Mason and Waywood 1996, p. 1058). They therefore refer to ontological and epistemological ideas as well as their methodological implications for investigating specific topics (cf. Bikner-Ahsbahs and Prediger 2010). In the present study, we choose to conceptualize

\footnotetext{
${ }^{3}$ See Schindler (2014, p. 95-104) and Stephan and Akyuz (2012, p. 430f) for an overview on research addressing out-of-school contexts and their role in the learning and teaching of negative numbers.
} 




Fig. 1 Perspectives on integers and the shifts of perspectives

reasoning by means of the philosophical theory of inferentialism. We think that every theory in mathematics education rests on underlying, fundamental philosophical theories with their particular strengths and weaknesses, emphases, and blind spots. We see that inferentialism has other strengths and emphases than commonly used background theories such as constructivism and, thus, may offer different viewpoints and insights when applied in mathematics education and empirical studies.

Noorloos et al. (2017) argued that inferentialism can overcome several philosophical problems that have continued to plague socioconstructivism such as the relation between the social and individual, relativism, and the question of what is constructed according to constructivism. At the same time, inferentialism seems consistent with several pedagogical implications of constructivism that could be judged separately from their problematic philosophical underpinning (cf. Phillips 1995; Mackrell and Pratt 2017). Inferentialism offers a pragmatic and social account of reasoning. It views reasoning as emerging from situations in which persons are involved; and as still social when persons draw on this reasoning later on, in other situations and settings - even when thinking alone (cf. Roth 2016b, Sfard 2008). Therefore, an inferentialist account of reasoning emphasizes how prior experiences influence students' reasoning. In particular, it assumes that students are (consciously or not) responsive to norms that they encountered in their earlier out-of-school and school lives; and that these norms guide their reasoning - even when reasoning alone. When a student, for instance, argues that -2 is greater than -5 because it is further right on the number line, she may be following the norm in the mathematics classroom that the number line is normally used for comparing negative numbers. The proposed inferentialist account regards students' out-of-school reasoning and mathematics reasoning as intertwined, does not separate them from one another, and does not privilege one over the other. Hence, it offers advantages especially in studies where students reason on the basis of both out-of-school phenomena and prior school experiences. The externalist account of reasoning, where the reasoning itself rather than students' internal mental representations or "underlying" mental models are considered, has positive consequences for methodological concerns; it offers a fine-grained in-depth account of students' reasoning.

\section{Philosophical background on inferentialism}

Brandom's $(1994,2000)$ contemporary philosophy of inferentialism draws on philosophical ideas offered by, for example, Kant, Hegel, Frege, Wittgenstein, and Heidegger. A key concept in inferentialism is the Kantian notion of judgment (Kant 1781/ 1999). Judgments are to be understood as claims that persons make explicit. In 
inferentialism, "[j] udgments are fundamental, since they are the minimal unit one can take responsibility for on the cognitive side, just as actions are the corresponding unit of responsibility on the practical side" (Brandom 2000, p. 159f). The meaning of concepts is to be understood in their roles in judgments.

As inferentialism is a semantic theory (cf., Noorloos et al. 2017), it aims to explain the use and content of concepts (cf. Brandom 2000). Content of concepts is conceptualized according to the inferential structure and role of judgements. Brandom (2000) states that "the guiding idea is that the essential feature distinguishing what is propositionally contentful is that it can serve both as a premise and as the conclusion in inferences" (p. 161). Thus, in an inferentialist perspective understanding can be conceptualized as the "mastery of properties of theoretical and practical inference" (Brandom 1994, p. 5), where inferential relationships exist between sentences, which have a propositional content (Brandom 2000). The focus on a system of inferentially linked judgments leads to a holistic perspective:

One immediate consequence of such an inferential demarcation of the conceptual is that one must have many concepts in order to have any. For grasping a concept involves mastering the properties of inferential moves that connect it to many other concepts: those whose applicability follows from the applicability of the concept in question, those from whose applicability the applicability of the target concept follows, those whose applicability precludes or is precluded by it (Brandom 1994, p. 89).

Inferentialism is rooted in pragmatics (Bakker and Derry 2011). This is to say that judgments are expressed and take the role as reasons in the language practice and that the view on the reasoning itself is prioritized over the view on students' representations (cf. Noorloos et al. 2017). Brandom (1994, 2000) introduces the metaphor of the game of giving and asking for reasons (GoGAR) for describing the social and pragmatic language practice in which the content is inferentially constituted. In the GoGAR, linguistic expressions and intentional states gain their meaning by virtue of the position that they have in a network of possible and actual doings (Bakhurst 2011). Making judgments and expressing reasons implies making moves in this game, which means "doing something in a social environment and, in virtue of this, changing the environment - which allows us to treat communication as a socially grounded production and consumption of reasons" (Kiryushchenko 2015, p. 1). Thus, reasoning is crucial for the meaning that is derived in situations. Accordingly, concepts are to be understood in their use in reasoning processes (Bakker and Derry 2011).

\section{Epistemological considerations derived from inferentialism}

Students' reasoning is social, as is situated in the GoGAR or derived from it (primacy of the social) We assume that mathematical reasoning is primarily social. When speaking of the social nature of reasoning, we do not mean that students get together and negotiate their different individual knowledge, as constructivists would put it (see also Roth 2016b). In our inferentialist perspective, we rather think that reasoning is social in the way that it consists in the GoGAR. Here, the participants make claims, they attribute claims to others, acknowledge other students' or the 
teacher's claims, they undertake them themselves, etc. The reasoning emerges socially. All participants in the GoGAR may have influence on the reasoning via making claims, also the teacher or interviewer. We think that students' reasoning is always social-even when they are talking to themselves or writing down their reasoning solely-because it has a social origin and the social situations are reflected in students' reasoning. When a student reasons that -5 is smaller than -2 because it is further left on the number line, this reflects preceding social situations; it might, for instance, reflect the social situation in which the student got used to this kind of reasoning in the mathematics classroom. Whereas social constructivism assumes that individuals build their individual knowledge in a social context and that students negotiate their individual knowledge, inferentialism connects to Roth's assumption that "[m]athematical reasoning is social through and through" (Roth 2016 b, p. 126). Inferentialism does not aim at isolating individual knowledge from social reasoning, nor does it try to abstract individual mental models or representations from students' utterances - it rather looks at the reasoning itself. When a student utters that -5 is greater than -2 because $-5{ }^{\circ} \mathrm{C}$ is colder than $-2{ }^{\circ} \mathrm{C}$, then this might reflect a situation from real life, where the child compared temperatures together with her siblings. Inferentialism asks for such inferences and for their origins, for the experiences that students draw on in their reasoning. In this line of thought, an inferentialist epistemology does not prioritize students' mathematical reasoning over out-of-school reasoning; nor does it view mathematics and out-ofschool reasoning as separated from one another, but rather as inferentially connected to one another. In sum, the proposed inferentialist epistemology emphasizes inferences that students draw from different experiences, from out-of-school life, from the mathematics classroom, from different contexts, and different external representations, such as the number line.

Students' reasoning in the GoGAR is implicitly normative (normativity) Situations in which students claim and reason about mathematics go along with certain norms about how to do things - how to talk, how to behave, how to reason, etc. Participants in the GoGAR are confronted with, for example, social expectations, didactical contracts, and rules - which often may remain implicit. In our perspective, students' reasoning takes place in implicitly normative situations. If a student was asked which of two numbers is greater, she would probably answer and reason in different ways according to the norms of the social situation, which she perceives to encounter. The proposed inferentialist perspective asks for such normative influences in the GoGAR and is sensitive for normative aspects in students' reasoning.

Students' concepts are not isolated from one another (holism) We understand students' reasoning in a holistic way. This is to say that concepts are connected to one another via their use and roles in students' claims in reasoning. When a student, for instance, argues that negative numbers are smaller than positive numbers because they are further left on the number line, then a whole "package" of interconnected concepts is involved: negative number, positive number, number line, etc. Instead of regarding the concept of negative number isolated, the inferentialist account emphasizes the interconnection of concepts in students' reasoning; for 
instance, the inferential linkage to the concept of natural number, minus sign, zero, subtraction, the number line, etc.

\section{Research questions}

Drawing on the inferentialist theory, we ask the following research questions.

1. When students compare negative numbers before having been part of a lesson series on negative numbers: how do they reason on the order relation for integers? What experiences do they draw on when comparing negative numbers, especially how are out-of-school and prior school-based experiences involved in their reasoning? What inferences do they draw from them?

2. When students compare negative numbers after having been part of a lesson series on negative numbers: how do they reason on the order relation for integers? Is this reasoning different from before the lesson series? To what extent do they draw on different out-of-school or school-based situations than before? How do they draw inferences from these situations?

\section{Method}

\section{Design of the study}

We use data from an empirical study conducted by Schindler (2014), which was carried out with sixth-grade students in a German secondary school. Eight students, ages 11, 12, and 13 years, participated in the study. The group consisted of six boys and two girls with German as their native language. The school was in a town of 75,000 inhabitants. See Fig. 2 for the design of the empirical study. Whereas the data analysis was conducted for eight students (cf. Schindler 2014), this paper focuses on data from two students, whose reasoning was diverse. Tom is a male student whoaccording to the teacher's information - is a strong student in mathematics. Nicole is a female student who is described as weak mathematics learner by her teacher. We choose these students for illustrating the range of students' reasoning; drawing on out-of-school and prior school-based experiences. However, neither of them reasons mathematically correctly before the lesson series; so, for both students, there is potential to develop their reasoning over the lesson series. In the post interviews, both students reason ambiguously for the order relation, pointing out that different ways of reasoning are possible. However, the students have different reasons for doing so.

\section{The interviews}

Studying students' reasoning in an inferentialist perspective has implications for the design of empirical investigations. An inferentialist design requires situations in which students are explicitly encouraged to make explicit their reasons and inferences, the origins of their inferences, and the prior experiences that they draw on. Thus, we 




Fig. 2 Design of the empirical study and data used in this paper

conducted semi-structured, task-oriented clinical interviews (see Selter and Spiegel 1997). Following the research questions (on students' reasoning before and after a lesson series) both before and after the lesson series.

The interview scheme In the single interviews, the students were repeatedly asked to determine which of two numbers was greater (positive/positive; positive/ negative; negative/negative). In particular, we wanted to analyze students' reasoning when encountering the symbolic representation of negative numbers. Results of previous studies had indicated that most of the students seem to know the symbolic representation and interpret the minus sign as a predicative sign (Beatty 2010; Bofferding 2010; Vlassis 2004, 2008) even before the introduction of negative integers at school (cf. Human and Murray 1987; Malle 1988; Peled et al. 1989). The interviewer explicitly asked the students to give reasons; for instance, asking "Why's that?," "How did you think about it?," or "Can you explain to me how you think about this?" Additionally, she asked for the origins of the inferences, for example, "How did you get the idea to ...?" or "Where do you know this from?"

The anticipated reasoning As Pierson-Bishop et al. (2014a) as well as Bruno and Cabrera (2005) found, a cardinal representation of negative integers can constitute an obstacle for students and it is rarely used by students when reasoning on the order relation for integers. On the other hand, the number line constitutes a cognitive affordance for the students. Therefore, we assume that an inference such as the further right a number on the number line, the greater it is (for the whole, continuous number line) best captures the mathematical valid order relation in students' perspective. According to the numbers involved (negative/negative; negative/positive; positive/positive), we expect students to draw on different concepts and reason differently (e.g., the concept of negative number for the comparison of two negative numbers). We assume that experiences with natural numbers, the comparison of natural numbers, and experiences within out-of-school contexts such as temperatures or debts-and-assets serve as an origin for students' inferences in the prior interviews. In the post interviews, we expect students to draw rather on their experiences in the lesson series (see "The lesson series and learning environment" section). 


\section{The lesson series and learning environment}

From an inferentialist perspective, learning environments and lesson series should encourage students to be involved in the GoGAR, where they can draw on out-ofschool experiences, to reason accordingly, and to inferentially relate their reasoning to external representations. Following these thoughts, we use a learning environment ("Out of the Debts") that has been developed by researchers (see Hußmann and Schindler 2014a, b) in a research and environmental project, KOSIMA, which aims at teaching mathematics through the use of real contexts (Hußmann et al. 2011). The first pivotal aspect of the learning environment is the use of an authentic, rich out-ofschool context, the context debts-and-assets. Empirical research has indicated that students often have certain experiences with this out-of-school context that they can draw on (Bruno et al. 2001); they use this context more often in their reasoning than, for instance, temperatures or heights (Bruno 1997), and can successfully draw on this context for integer addition and subtraction (Stephan and Akyuz 2012). Second, the use of the number line (Stephan and Akyuz 2012; Beatty 2010) is fundamental for the learning environment and the lesson series, as it can serve as origin for students' inferences on the existence of negative numbers, their position, and on a mathematically correct, continuous counting and order relation (cf. Bruno and Martinón 1997).

In the beginning of the lesson series, the students play the board game "out of the debts" in groups of four. In this game, every student is in the role of an indebted person aiming at redeeming their debts. The board is a number line (called "account bar"), containing positive and negative numbers. Using different action cards that the students draw before and during the game, they individually have their current account balances, monthly incomes, and monthly expenses. Many real-life aspects are involved (such as the possession of luxury goods, surprising events leading to money loss or gains, etc.). In every round of the game, the players draw their changing account balance with their piece on the board, i.e. the number line. When their balance, for instance, was $-1000 €$ initially, they have an income of $800 €$ and expenses of $700 €$, then they draw the piece from $-1000 €$ to $-200 €$ to $-900 €$. In our study, we found that the students reflected on the context; for example, on the possession of too many luxury goods ("I do not really need a car!" or "I don't want riding lessons if I can't afford them."). In the further lesson series, the students deal with various mathematical problems in which contextual and number line experiences are picked up in students' reasoning. Problem 2, for instance (Fig. $3^{5}$ ), invites the students to reflect on their experiences in the game andmathematically speaking - on the different ways of reasoning on the order relation, on the position of the numbers on the "account bar," and the role of the minus sign in this context. Problem 2 (a) and (b) aim at encouraging students' reasoning on the size of the numbers based on their positions on the number line, whereas problems 2 (c) and (d) give the students the opportunity to reflect on the role of the minus sign for debts.

Besides the main context debts-and-assets, other contexts such as temperatures and altitudes are used. Many activities aim at practicing to change representations (Fig. 1).

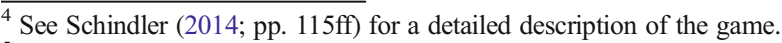

${ }^{5}$ Figure reproduced and translated from Hußmann and Schindler (2014a, p. 75).
} 
2 More or less debts

In the following problems, you are inquiring into the game "Out of the Debts".

a) Till's and Ole's household cards display different debts. Till has a debt of $300 €$, whereas Ole has a debt of $400 €$. Both put their pieces on the account bar. Have a look at Ole's claim. What do you say? Who has more?

b) Draw the account bar from $-500 €$ until $+500 €$ in your exercise book. Mark Till's and Ole's account balances. Use the account bar to explain who has more money on his bank account.

c) Have a look at the other students' account balances and also mark them on the account bar.
Pia: debt $200 €$
Till: $-300 €$
Nina: $\quad 100 €$
Emre: asset $200 €$
Ole: $-400 €$
Merve: asset $300 €$

d) Explain what the minus sign in front of Till's and Ole's numbers means. Why is there no sign in front of Nina's number?

Fig. 3 Example of a mathematical problem in the learning environment and lesson series (cf. Hußmann and Schindler 2014a, p. 75)

\section{Data and data analysis}

The interviews are videotaped and the videos are transcribed. Students' written notes (written numbers or drawings) are scanned and inserted in the transcripts. For the data analysis, the whole transcripts are used as long as they address the topic. The data analysis focuses on the aspects addressed in "Epistemological considerations derived from inferentialism" section.

\section{Results}

\section{Illustrating students' reasoning before the lesson series-preliminary interviews}

\section{Tom's reasoning based out-of-school experiences}

In the preliminary interview, Tom is asked to tell which of two numbers is greater (the numbers are listed in the left column of Table 1).




The initial invitation by the interviewer (Turn 001) gives reasons for Tom to make a claim about the size of the numbers. Here, Tom claims that 12 is greater than -15 (Turn 004). The interviewer's question "Mhm?" encourages him to give a reason. His reasoning, then, is based on the assumption that numbers below zero are smaller than "normal" numbers (Turn 006). When asked for further reasons, Tom argues that there are negative numbers on a thermometer. Here, the thermometer seems to be an important out-of-school concept for him. For Tom, who has not dealt with negative numbers at school before this interview, experiences with a thermometer that he was involved in within the out-of-school context of temperatures are crucial in his reasoning. On the thermometer, he has seen that the negative numbers are below zero. The position above or below zero on the thermometer is, thus, an important concept for him.

Later on, the interviewer asks Tom to determine which number is greater, 6 or -9 (Turn 014). Tom claims that 6 is greater than -9 . He preserves the reasoning of the previous episode, explicitly claiming "This is just like the one just before" (Turn 015). After the interviewer's question, "Can you explain this again?" (Turn 016), the student states that numbers below zero are below the freezing point and that numbers above zero are normal numbers and not minus numbers (Turn 017). As he uses this claim to justify his initial claim (that 6 is the greater number), he again seems to reason that negative numbers, which are below the freezing point, are smaller than natural numbers, which are above zero. He provides a similar reason to his previous and explicitly draws on reasoning from the previous situation. Again, he draws on his experiences in the out-of-school context of the thermometer. In particular, Tom's reasons in judging the sizes of a negative and a positive integer seem to a great extent to be based on the role of zero, which serves as a significant concept in his inference. In the full interview, Tom deals with two more similar situations where he also uses the same reasoning pattern (see Table 1).

Furthermore, Tom is asked to compare two negative numbers (see Table 1). In these situations, new reasons guide his reasoning. In the first situation, he is asked to determine which number is greater, -31 or -27 . After $6 \mathrm{sec}$, he says " 31 . Minus 31 . Because the numbers- because the number is greater on its own. Even if it had no minus, it would still be greater than 27" (Turn 21), claiming that -31 is greater than -27 . He makes his reasons explicit: The concept he draws on is the size of the number "on its own." We can interpret his statement as if he (mathematically speaking) uses the concept of the absolute value of the numbers (though he most likely does not

Table 1 Tom's reasoning

$\begin{array}{ll}\begin{array}{l}\text { Situation with regard to the } \\ \text { numbers }\end{array} & \begin{array}{l}\text { Reasoning } \\ 12 \text { and }-15\end{array} \\ 9 \text { and }-6 & \text { Basic concept involved: (below) zero } \\ 9 \text { and }-9 & \text { Basic inference: The positive number is greater than the negative number, } \\ 0 \text { and }-9 & \text { Bhich is below zero. } \\ -27 \text { and }-31 & \text { Basic inference: The number that has the greater absolute value is greater. } \\ -7 \text { and }-11 & \\ -1 \text { and }-9 & \\ -1 \text { and }-4 & \end{array}$


consciously do so). The number that has the greater absolute value is the greater number in his way of reasoning. He certainly is trying to cope with a difficult, new situation based on the reasoning that he is familiar with from other situations. Being asked how he thinks about it (Turn 022), he says "Well, now I do not have any image whatsoever" (Turn 023). One reason could be that Tom has not experienced such cold temperatures and has not seen them on a thermometer before (temperatures of about $-30{ }^{\circ} \mathrm{C}$ do usually not occur in the part of Germany that he is living in). This could be a reason for him to ignore the minus sign in order to handle this situation. Thus, he most likely draws on prior experiences related to experiences with natural numbers and his reasoning can be linked to what is called a "divided number line model" (Peled et al. 1989, Mukhopadhyay 1997). Tom shows the same reasoning when asked to compare -11 and -7 . Here, he immediately answers "Minus 11." (Turn 025) and draws on the same reasoning as in the situation before claiming, "This is like just before" (Turn 025). He continues to make his reasons explicit, saying, "11 is greater than 7 . Even if it was without the minus" (Turn 025). He again seems to use the concept of absolute value, similarly to the previous situation. The reasoning in both situations is characterized by the same basic inference, which can be paraphrased as "the number that has the greater absolute value is the greater number." The same is true for two more situations in which Tom determines the greater number (among -1 and -9 , and -4 and -1 ). Here, he applies almost identical patterns of reasoning in the GoGAR. However, when being asked how he thinks about it when comparing -1 and -4 , he again refers to these temperatures on the thermometer. It appears as if he, in this case, can recall experiences with temperatures that he has "seen" on the thermometer.

\section{Reasoning and understanding based on the concept of natural number and previous} experiences with arithmetic tasks - the case of Nicole

In the following, we will — due to space restrictions - describe our interpretation of the data in a more concise way, giving overviews on our evaluation. In the preliminary interview, Nicole is asked to tell which of two numbers is greater (the numbers are listed in the left column of Table 2). The interview starts with the interviewer asking Nicole to determine which number is greater, 12 or -15 (Turn 001). She responds after $6 \mathrm{sec}$ "The fifteen. (another $6 \mathrm{sec}$ ) No the twelve, because there at- in front of the fifteen there is- minus fifteen is displayed there, then it has to be the twelve" (Turn 002). Her reasoning, in which she revises her initial claim, indicates that she draws on the concept of minus sign in this situation. From a subject matter perspective, this is correct: negative numbers are smaller than positive numbers.

Table 2 Nicole's reasoning

$\begin{array}{ll}\begin{array}{l}\text { Situation with regard to the } \\ \text { numbers }\end{array} & \text { Reasoning } \\ 12 \text { and }-15 & \text { Basic focus: subtraction } \\ 6 \text { and }-9 & \begin{array}{l}\text { Basic inference: The number is greater which is still greater after } \\ \text { subtraction. }\end{array} \\ 14 \text { and }-13 & \text { Basic focus: absolute value } \\ 4 \text { and }-3 & \text { Basic inference: The number that has the greater absolute value is greater. }\end{array}$


However, the next turns in this episode reveal that Nicole's reasoning is different than expected.

\begin{tabular}{lll}
\hline Turn & Speaker & Statements \\
003 & I & Mhm? How did you think about this? \\
004 & $\mathrm{~N}$ & $\begin{array}{l}\text { Well, let's say, when we take twelve minus fifteen, then we'd have less than twelve. And then, } \\
\text { the twelve is greater. }\end{array}$ \\
005 & I & $\begin{array}{l}\text { Mhm? Okay, now you've created an arithmetic problem out of it, right? How did you get the } \\
\text { idea of creating an arithmetic problem out of it? }\end{array}$ \\
006 & $\mathrm{~N}$ & $\begin{array}{c}\text { Because there, well (putting the cards next to each other, displaying: 12-15), it is, let me say, } \\
\text { cut out. Because the twelve is a number (pointing to 12) and then, the minus is already } \\
\text { there (pointing to the minus sign), and then f- } \mathrm{m} \text { - } \mathrm{f}-\text { minus fifteen and then it is actually a } \\
\text { mathematical problem. }\end{array}$ \\
&
\end{tabular}

Apparently, Nicole uses her concept of subtraction and assumes that the two numbers form an arithmetic problem. Her reasoning reflects that she grasps the situation as a subtraction task. It is apparent that her reasoning in this situation is very different from what was expected after she had answered the question initially correctly in Turn 002. Her reasoning reflects a use of the minus sign as an operative sign (cf. Vlassis 2004) although the first statement had indicated that she uses the minus sign as a unary, predicative sign (cf. Vlassis 2004).

In our inferentialist analysis, we wonder why she thinks that her focus on subtraction is compatible with the invitation to determine the greater number; and how she perceives the situation. One reason could be that some German students tend to use a subtraction strategy in order to figure out which of two natural numbers is greater. If the subtraction "works" (i.e., results in a positive number), then the first number is greater. Such strategy is indicated, among others, by her reasoning later on in the interview. When comparing two numbers, she explicitly tries if "it works" to subtract the numbers; here, she writes them below each other to see if long subtraction "would work." Even though we cannot be entirely sure about her reasoning in the abovementioned initial episode, this indicates at least that a focus on subtraction and comparison are not opposed each other. Prior experiences like this could be a reason for Nicole to focus on subtraction and would explain why the focus on subtraction is compatible with the focus on comparing numbers. Her utterances in a later episode in the interview furthermore hint at the prior scholastic experiences she draws on. Asked, "Where do you know this from, regarding the minus sign?" (Turn 019) by the interviewer, she answers "I have done this in primary school [remark: grades 1-4 in Germany]. Well, there we also had arithmetic problems. There, there stood, let's say, only minus six at the end. And then you have to find out the number in front. That's almost the same." In a further situation, in which Nicole gets the cards 9 and -6 , she explicitly refers to the similarity of the situations and her reasoning follows the same pattern. In her reasoning in the second situation, she adds that the second number (in her situation, i.e., in the task 6-9) gets smaller, whereas the first one "stays as it is." Even though her proceeding is not correct and difficult for us to understand, it is consistent across these two situations, which she perceives to be similar.

However, when being asked to determine the greater number among 14 and -13 Nicole finds herself in a different type of situation, which her reasoning hints at. 
After $14 \mathrm{sec}$, she answers "The fourteen, I'd say, but... (another $5 \mathrm{sec}$ ) (nodding) The fourteen, because it is one point higher. And now, one cannot, like min- these numbers, well, cannot take 14 minus 13." (Turn 063). Here, she uses the concept of absolute value of the numbers (even though she most likely does not consciously do so), because in her view it is not possible to subtract 14 minus 13. Probably, the reason for focusing on absolute values in this case lies in her prior (school-based and out-of-school) experiences with the comparison of natural numbers. She is again trying to transform the new and challenging situation into a situation that she can handle and that is familiar to her. She uses the same pattern of reasoning later on when she is asked to determine which number is greater, 4 or -3 , and explicitly refers to the similarity of the situation. In both situations (14 and $-13 ; 4$ and -3 ), she intermediately focuses on subtraction and tries to subtract, but finally comes back to the focus on the absolute values. In these two situations (14 and $-13 ; 4$ and -3$)$, it becomes apparent that her pattern of reasoning is different from the pattern of reasoning in the two other situations (12 and $-15 ; 6$ and -9 ; see Table 2), depending on the absolute values of the numbers.

Even though she gives the correct answer on the first try in all four situations (see Table 2), the reasoning in the inferentialist setting reveals that she does not interpret the minus sign as a predicative sign (Vlassis 2004) and how she accordingly draws on other concepts than expected, such as subtraction and the absolute values of the numbers. Her reasoning in these situations, which may seem arbitrary, illogical, or inconsequent at first glance, follow her individual logic.

\section{Illustrating students' reasoning after the lesson series-post interviews}

In the following, we focus on the comparison of two negative numbers, which were the critical instances in the post interviews. Both students were able to handle comparisons of positive and negative numbers easily by drawing on their position with regard to zero (Tom) or on the number line (Nicole). Therefore, these episodes are left out below due to space restrictions.

\section{Changing patterns of reasoning - the case of Nicole}

Nicole's case is an example of a student whose reasoning of the order relation is not settled after the lesson series. This gives us the chance to see how her reasoning and the concepts involved change during the post interview.

\footnotetext{
Turn Speaker Statements

001 I I brought along two numbers and I want you to tell me which one of them is greater (gives two small cards to the student, displaying -8 and -12 )

$002 \mathrm{~N}$ (looking at the cards) (5 s) Well, on the number line, this one would be greater (pointing at -8 ), but otherwise, this one is greater (pointing at -12 ).

003 I Mhm?

$004 \mathrm{~N} \quad$ Because on the number line, there is minus (pointing at the minus sign in front of -8 ). And if we have such a number line (showing an imagined horizontal line on the paper), then this one is greater (pointing on -8 ), and this one then smaller (pointing on -12). And, er, otherwise, this one is greater (pointing on -12 ).
} 
Nicole's reasoning is following two different patterns, depending on the form of external representation: one can either compare negative numbers on the number line, making -8 the greater number, or compare them "otherwise" making -12 greater. Her distinction leads to the question of where these two ways of reasoning originate. This does not become clear in her statements, as she does not make explicit what she focuses on when claiming that -12 is greater "otherwise" and as the interviewer does not ask for further explanation. Her reasoning indicates that she draws on the concept of absolute value of the numbers, disregarding or (mentally) deleting the minus signs. We interpret that the reasoning during the lesson series, in which the number line had a major role, had influence on her reasoning here. In the context of the lesson series, she was encultured to focus on the number line and reason accordingly; probably, she is following this norm in the post interview. On the other hand, she has focused on natural numbers and the absolute value in the preliminary interview. She seems to point out the different "rules" of the games consciously.

Then, the interviewer asks her to draw the numbers on the number line.

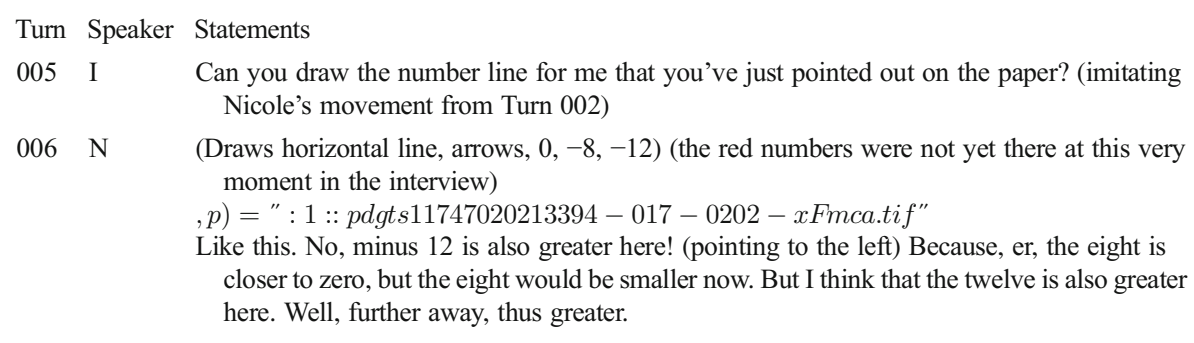

The drawing of the number line gives Nicole reasons to change her reasoning. Now, in both situations, she considers -12 greater. The question arises of what reasons she has to change her claims. She draws on the distance to zero as a main concept and argues that the number, which is closer to zero, is smaller; whereas the number that is further away is greater. This way of reasoning relates to a "divided number line model" (Peled et al. 1989, Mukhopadhyay 1997). Still, the question remains of what reasons Nicole has for revising her claim that -8 is greater on the number line (Turn 002) and to assume that the inference "the further away from zero, the greater the number is" is valid for negative numbers as well. Possibly the fact that the interviewer asks her to draw a number line gives reasons to her to assume that the previous claim was wrong.

At a later moment in the same interview, Nicole is comparing -11 and 14 , reasoning that 14 is greater because 14 is in the positive area on the number line, right to zero. After drawing +14 on the number line and claiming "And here then is plus fourteen, that's why it is greater, because it's plus", she directly continues as follows:

Turn Speaker Statements

$008 \mathrm{~N} \quad$ But I again have to correct myself here because, er, er, if it is plus here (pointing at the positive part of the number line), then the eight (pointing at eight on the number line) is 
Turn Speaker Statements

greater than twelve after all. One has to envision that is goes towards plus (pointing to the right) and then the minus eight was, er, there, er, greater.

And here (referring to the present task) plus 14 is greater (pointing at +14 on the number line).

009

Okay and here, well the, what did you exactly mean? Do you mean that the minus eight is greater than minus twelve?

$010 \mathrm{~N} \quad$ Yes.

011 I Mhm, okay, I just want to get you right. And why is it like this?

$012 \mathrm{~N}$ Because it (minus eight) $\mathrm{mh}$, is closer to zero and because it goes up there. (pointing to the right from zero onwards on the number line) And, er, because it is then closer therefore it is greater. And because if you have minus, then it is smaller. If you are up, or closer to up (pointing up), well at plus is it greater then.

In this episode, Nicole consciously revises her reasoning again-finally towards the mathematically correct reasoning. It appears to be the focus on the positive area on the number line and the idea of "going" towards this positive part that helps her to draw the mathematically correct inference "the further right on the number line, the greater the number is." Her inference could be described as the less you have to go to the positive part, the greater the number is. Here, a dynamic view on the distance to zero or the positive part on the number line is guiding her reasoning. In the subsequent episode, in which Nicole deals with the task to compare -28 and -33 , she reasons straightforwardly in the way she did in this last episode, indicating that she does not seem to question the order relation any longer-it seems to be a logical necessity (Pierson-Bishop et al., 201a) for her.

In the end of the post interview, Nicole and the interviewer talk about different contexts (among others about heights below sea level and debts). When comparing the heights 250 and $325 \mathrm{~m}$ below sea level and being asked what is higher, she directly utters, " $250 \mathrm{~m}$ because this is just like a number line (indicating a vertical line). Here is the sea, like a dash (making a marking with her finger on the vertical line), and here is $250 \mathrm{~m}$ (putting her finger below the dash) and here is $300 \mathrm{~m}$ (putting another finger below the last one). Then this one (wiggling with the $-250 \mathrm{~m}$-finger) is closer because it goes up here (moving the finger up)." Her reasoning has apparent similarity to her reasoning in Turn 012. It appears that she draws on the revised reasoning that she has developed during the post interview. We elaborate further on Nicole's reasoning in the post interviews and the changes over the lesson series in "Discussion and conclusions" section.

\section{Two possible ways of reasoning - the case of Tom}

In Tom's post interview, he points out that the comparison of -8 and -12 can be considered in two different ways: the mathematical correct reasoning on the number line and the reasoning focusing on the absolute value within the context of debtsand-assets. After receiving the cards, he quickly answers, "the minus eight is greater because it is closer to zero. ( $5 \mathrm{~s})$ Yes, and when a number is closer to zero, then it is greater. If there stood, however, when, say, er, which number, well which debts are greater, then it would be the minus twelve" (Turn 002). This distinction is reasonable and makes - in certain situations - sense. Of course, a $12 €$ debt is a greater 
debt than an $8 €$ debt. His statements reflect that he is aware that the second understanding has a minor significance in the mathematical context. If we have a look at the GoGAR in Tom's preliminary interview and the GoGAR in the lesson series, we can find reasons for his distinction. In the preliminary interview, the GoGAR was characterized by Tom's focus on the absolute value of the numbers. The focus on the absolute value was crucial for his reasoning and his basic inference "the number that has the greater absolute value is the greater number." During the lesson series, the students made various experiences with the number line and with the context debts-and-assets (Hußmann and Schindler 2014a, b). Mathematical problems used in the lesson series (Fig. 2) aimed at creating a GoGAR in which students reflect on the two possible ways of reasoning. Tom is possibly drawing on these experiences.

\section{Discussion and conclusions}

The purpose of this article was to investigate how students draw on out-of-school and school-based experiences when reasoning on the order relation for integers and how they infer from these experiences. Using inferentialism, we highlighted different aspects of students' reasoning, especially asking for the reasons students have, for their origins, and related prior experiences. The preliminary interview with a strong student, Tom, illustrated how students may infer their reasoning on negative numbers from out-of-school experiences. It confirmed existing results indicating that students tend to use out-of-school experiences when reasoning on negative numbers (Bruno and Cabrera 2005). From the context of temperatures and the significance of the freezing point, Tom inferred the significance of zero for the distinction of negative and positive numbers; from the position of numbers on the thermometer, he inferred the position and size of positive and negative numbers. In comparison to Bruno and Cabrera's findings, the results from our inferentialist analysis give a more fine-grained account of how students draw on out-of-school contexts: what they infer, how they infer, and which concepts are significant. We additionally provided an account of what a "divided number line model" (Peled et al. 1989) means in Tom's case and what his reasons are. For the comparison of two negative numbers, he focused on absolute values, probably drawing on prior experiences with natural numbers, disregarding the negative signs of the numbers. This connects to Bofferding's (2014) finding that natural number concepts can have a strong impact on students' reasoning with negative numbers. Tom's case illustrates how difficult it can be even for strong sixth graders to make use of out-of-school contexts when comparing two negative numbers.

The preliminary interview with the second student, Nicole, illustrated that students' initial answers can easily be misinterpreted. Whereas Nicole's initial answers to all questions were correct, the inferentialist focus on her reasoning and its origins in the data analysis revealed that she drew on the concept of subtraction and focused on the minus sign as subtraction sign while comparing a positive and a negative integer. This underpins the necessity to investigate students' reasoning (Pierson-Bishop et al. 2014a). If only the students' answers had been considered (e.g., in a written test), it would not have been revealed that Nicole drew on 
different experiences than we had expected, which were mathematically not valid. This also confirms the importance of research settings where students can explicitly be asked to reason about their answers. Although Nicole's reasoning might appear illogical or inconsistent at first sight, it followed a logic that she inferred from prior school-based experiences with comparing natural numbers; where she most probably "tested" which among two natural numbers was greater via subtracting them from one another and testing if "it works". Such a strategy has-to our knowledge - not yet been reported in empirical research on the order relation for negative integers. ${ }^{6}$ However, it connects Bofferding's (2014) finding that students tend to apply subtraction strategies from whole numbers to negative numbers and to Pierson-Bishop et al.'s (2014a) finding that students search for underlying structures and principles and use these logically to infer what is possible and appropriate and what cannot be. Nicole's case showed how students' individual logic may differ from the mathematical logic and still follow their individual principles across different situations. When comparing two negative numbers, Nicole's reasoning focused on the absolute value of the numbers. This can - as Tom's reasoning-be related to what is called a "divided number line model" (Peled et al. 1989). However, the two students' reasoning differed a lot; among others regarding the use of out-of-school experiences, the prior school-based experiences they drew on, the level of correctness, and especially whether the students' drew on the minus sign as subtraction or predicative sign in their reasoning (Bofferding 2010; Vlassis 2004, 2008). This confirms our assumption that the "divided number line model" as a category has a broad scope that may be inattentive to the differences that students' individual reasoning implies. Our results indicate that a more sophisticated account of students' reasoning, as proposed in this paper, is beneficial for being able to understand them appropriately.

The post interviews of both students illustrate that even after a lesson series on negative numbers, students' reasoning on negative integers and the order relation for integers is manifold. Our results support the finding that students have the ability to switch perspectives, to reason differently, and to be able to draw flexibly on different prior experiences and inferences when comparing negative integers; and that this ability offers affordances for students (cf. Pierson-Bishop et al. 2014 b). Both students inferred their reasoning from the number line, an external representation that was crucial in their lesson series. This illustrates the impact that students' school-based experiences during a lesson series have on students' reasoning on the order relation for integers (similar to Stephan and Akyuz 2012, finding on contexts for integer calculation; cf. Beatty 2010).

The results of the post interviews revealed that their reasoning varied largely. Tom distinguished two different kinds of reasoning (the mathematically correct order relation, inferred from the number line; and the reasoning based on absolute values, inferred from the context debts-and-assets), and maturely pointed out that these two perspectives each are feasible, depending on the context. Nicole, on the other hand, discarded her way of reasoning twice, indicating that her experiences during the post interviews still influenced and changed her way of reasoning; with changing focuses.

\footnotetext{
${ }^{6}$ The fact that a second student in our study reasoned similarly indicates that this kind of reasoning is not a purely idiosyncratic phenomenon.
} 
This underpins our assumption that the order relation for integers may be challenging for students - even after the lesson series. From Nicole's case, we learned that students still can have insecurities regarding the order relation of integers after lesson series, what such insecurities can look like in detail, and what finally can help students to logically infer the mathematically correct order relation and according reasoning. In Nicole's case, it was a dynamic concept of distance to zero and the inference "the less you have to go to zero, the greater the number is" that helped her to change her way of reasoning towards the mathematically correct one.

Finally, the analyses and their results confirmed that inferentialism can offer a framework with which one can analyze students' manifold and sophisticated ways to reason on the order relation of negative numbers. Our findings would not have been revealed with perspectives that restrict their views to students' performances or to students' reasoning captured in certain categories or mental models. Even though we could relate our findings to such models (e.g., the divided or continuous number line model), these categories fall short if we want to understand more deeply why students answer problems in the way they do and why they reason in the way they do. Using an inferentialist account both in the design of the study and the analysis of the data offered us a new perspective on students' reasoning on the order relation of integers as well as results that have — at least partially — not revealed in such level of detail so far.

However, our study using inferentialism has - as any study - also its limitations. As in all qualitative studies, analyzing empirical data also in an inferentialist approach requires the researchers to draw inferences themselves: about what students meant when making a claim, which norms they were probably following, or even if a simple "yes" uttered by a student indicates that the student is carefully listening, indicates an agreement, or simply the intention to end up a discussion. Even though inferentialism does not aim at inferring mental models, representations, or (mis-)conceptions from students' utterances, it interprets students' reasoning, and thus has to infer from students' utterances. We cope with the concomitant scope of interpretation via thorough consideration of all given data and discussing various possible inferences in data analysis in a group of researchers.

Inferentialism is a semantic theory about concept use and concept content in terms of inferences. This means it has the potential to study the inferential nature of students' learning of mathematics, which we consider to be an inferential discipline. We also propose that the emphasis on inference in relation to representation counterbalances an emphasis on representation that is common in semiotic analysis (Peirce's focus on diagrammatic reasoning is an exception). However, inferentialism does not address the importance of tools or artifacts, for which sociocultural and activity-theoretical approaches or theories on instrumental genesis would be more suitable. Neither is it a psychological theory. Hence, in making inferentialism productive for the psychology of mathematics education nontrivial work still has to be carried out. We think that our work could potentially be the springboard for such further work. We furthermore hope-in a more general perspective - that our considerations and findings can lift the discussion within mathematics education research on the use of different background theories.

Open Access This article is distributed under the terms of the Creative Commons Attribution 4.0 International License (http://creativecommons.org/licenses/by/4.0/), which permits unrestricted use, distribution, and reproduction in any medium, provided you give appropriate credit to the original author(s) and the source, provide a link to the Creative Commons license, and indicate if changes were made. 


\section{References}

Bakhurst, D. (2011). The formation of reason. Oxford: Wiley-Blackwell.

Bakker, A., \& Derry, J. (2011). Lessons from inferentialism for statistics education. Mathematical Thinking and Learning, 13(1-2), 5-26.

Beatty, R. (2010). Behind and below zero: sixth grade students use linear graphs to explore negative numbers. In P. Brosnan, D. B. Erchick, \& L. Flevares (Eds.), Proceedings of the 32nd annual meeting of the North American chapter of the international group for the psychology of mathematics education (pp. 219-226). Columbus: The Ohio State University.

Bikner-Ahsbahs, A., \& Prediger, S. (2010). Networking of theories - an approach for exploiting the diversity. In B. Sriraman \& L. English (Eds.), Theories of mathematics education. Seeking new frontiers (pp. 483512). Berlin: Springer.

Bofferding, L. (2014). Negative integer understanding: characterizing first graders' mental models. Journal for Research in Mathematics Education, 45(2), 194-245.

Bofferding, L. (2010). Addition and subtraction with negatives: acknowledging the multiple meanings of the minus sign. In P. Brosnan, D. B. Erchick, \& L. Flevares (Eds.), Proceedings of the 32nd annual meeting of the North American chapter of the International Group for the Psychology of Mathematics Education (pp. 703-710). Columbus: The Ohio State University.

Borba, R. E. (1995). Understanding and operating with integers: Difficulties and obstacles. In L. Meira. \& D. Carraher (Eds.), Proceedings of the Annual Conference of the International Group for the Psychology of Mathematics Education (pp. 226-231). Recife.

Brandom, R. (2000). Articulating reasons: an introduction to inferentialism. Cambridge, MA: Harvard University Press.

Brandom, R. (1994). Making it explicit: reasoning, representing, and discursive commitment. Cambridge, MA: Harvard University Press.

Bruno, A. (2001). La enseñanza de los números negativos: formalismo y significado. La Gaceta de la Real Sociedad Matemática Española, 4(1), 415-427.

Bruno, A. (1997). La enseñanza de los números negativos: aportaciones de una investigación. Revista de didáctica de las matemáticas, 29, 5-18.

Bruno, A., \& Cabrera, N. (2005). Una experiencia sobre la representación en la recta de números negativos. Quadrante: Revista teórica e de investigação, 14(2), 25-41.

Bruno, A., \& Martinón, A. (1997). Procedimientos de resolución de problemas aditivos con números negativos. Enseñanza de las Ciencias, 15(2), 249-258.

Bruno, A., \& Martinón, A. (1996). Números negativos: una revisión de investigaciones. Revista de Didáctica de las Matemáticas, 9, 98-108.

Bruno, A., Martinón, A., \& Velázquez, F. (2001). Algunas dificultades en los problemas aditivos. Suma. Revista para la enseñanza y aprendizaje de las matemáticas, 37, 83-94.

Chiu, M. M. (2001). Using metaphors to understand and solve arithmetic problems: novices and experts working with negative numbers. Mathematical Thinking and Learning, 3(2-3), 93-124.

Davidson, P. M. (1987). How should non-positive integers be introduced in elementary mathematics? In J. C. Bergeron, N. Herscovics, \& C. Kieran (Eds.), Proceedings of the 11th International Conference for the Psychology of Mathematics Education (Vol. 2, pp. 430-436). Montreal, Canada: University of Montreal.

Duval, R. (2006). A cognitive analysis of problems of comprehension in a learning of mathematics. Educational Studies in Mathematics, 61(1/2), 103-131.

Gallardo, A. (1995). Negative numbers in the teaching of arithmetic: Repercussions in elementary algebra. In D. Owens, M. Reeds, \& G. Millsaps (Eds.), Proceedings of the Seventeenth Annual Meeting of the North American Chapter of the International Group for the Psychology of Mathematics Education (pp. 158-163). Columbus.

Human, P., \& Murray, H. (1987). Non-concrete approaches to integer arithmetic. In J. C. Bergeron, N. Herscovics, \& C. Kieran (Eds.), Proceedings of the international conference on the psychology of mathematics education (pp. 437-443). Montreal.

Hußmann, S., Leuders, T., Prediger, S., \& Barzel, B. (2011). Kontexte für sinnstiftendes Mathematiklernen (KOSIMA) - ein fachdidaktisches Forschungs- und Entwicklungsprojekt. In R. Haug \& L. Holzäpfel (Eds.), Beiträge zum Mathematikunterricht (pp. 419-422). Münster, Germany: wtm.

Hußmann, S., \& Schindler, M. (2014a). "Raus aus den Schulden"-Mit negativen Zahlen rechnen [out of the debts - calculating on negative numbers]. In T. Leuders, S. Prediger, B. Barzel, \& S. Hußmann (Eds.), Mathewerkstatt 3 [Maths studio 3] (pp. 47-78). Berlin: Cornelsen.

Hußmann, S., \& Schindler, M. (2014b). Ein Kontext für negative Zahlen - auch für die Multiplikation [a context for negative numbers - also for multiplication]. Mathematik lehren, 183, 28-32. 
Kant, I. (1781). Kritik der reinen Vernunft [critique of pure reason]. Cologne: Parkland.

Kiryushchenko, V. (2015). Semantic contents and pragmatic perspectives: the idea of objectivity in Robert Brandom's normative pragmatism. Paper presented at the "epc2: European Pragmatism Conference II". Retrieved from http://epc2.sciencesconf.org/54871

Mackrell, K., \& Pratt, D. (2017). Constructionism and the space of reasons. Mathematics Education Research Journal.

Malle, G. (1988). Die Entstehung neuer Denkgegenstände - untersucht am Beispiel der negativen Zahlen [the formation of new 'mental objects' - investigated using the concept of negative numbers]. In W. Dörfler (Ed.), Kognitive Aspekte mathematischer Begriffsentwicklung [cognitive aspects of mathematical concept formation] (pp. 259-319). Vienna: Hölder-Pichler-Tempsky.

Mason, J., \& Waywood, A. (1996). The role of theory in mathematics education and research. In A. J. Bishop et al. (Eds.), International handbook of mathematics education (pp. 1055-1089). Dordrecht, NL: Kluwer.

Mukhopadhyay, S. (1997). Story telling as sense-making: children's ideas about negative numbers. Hiroshima Journal of Mathematics Education, 5, 35-50.

Mukhopadhyay, S., Resnick, L. B. \& Schauble, L. (1990). Social sense-making in mathematics: Children's ideas of negative numbers. In G. Booker, P. Cobb, \& T. De Mendicuti (Eds.), Proceedings of the Annual Conference of the International Group for the Psychology of Mathematics Education with the North American Chapter 12th PME-NA Conference (pp. 281-288). Mexico.

Murray, J. C. (1985). Children's informal conceptions of integer arithmetic. In L. Streefland (Ed.), Proceedings of the Annual Conference of the International Group for the Psychology of Mathematics Education (pp. 147-153). Noordwijkerhout, NL: Technipress Culemborg.

Noorloos, R., Taylor, S., Bakker, A., \& Derry, J. (2017). Inferentialism as an alternative to socioconstructivism in mathematics education. Mathematics Education Research Journal, 1-17. doi:10.1007/s13394-017-0189-3

Peled, I. (1991). Levels of knowledge about negative numbers: effects of age and ability. In F. Furinghetti (Ed.), Proceedings of the Fifteenth Annual Meeting of the International Group for the Psychology of Mathematics Education (Vol. 3, pp. 145-152). Assisi, Italy: Conference Committee.

Peled, I., Mukhopadhyay, S., \& Resnick, L. B. (1989). Formal and informal sources of mental models for negative numbers. In G. Vergnaud, J. Rogalski, \& M. Artigue (Eds.), Proceedings of the Thirteenth Annual Meeting of the International Group for the Psychology of Mathematics Education (Vol. 3, pp. 106-110). Paris: France.

Phillips, D. C. (1995). The good, the bad, and the ugly: the many faces of constructivism. Educational Researcher, 24(7), 5-12.

Pierson Bishop, J., Lamb, L. L., Philipp, R. A., Whitacre, I., \& Schappelle, B. P. (2014a). Using order to reason about negative numbers: the case of Violet. Educational Studies of Mathematics, 86(1), 39-59.

Pierson Bishop, J., Lamb, L. L., Philipp, R. A., Whitacre, I., Schappelle, B. P., \& Lewis, M. L. (2014b). Obstacles and affordances for integer reasoning: an analysis of children's thinking and the history of mathematics. Journal for Research in Mathematics Education, 45(1), 19-61.

Roth, W.-M. (2016a). Concrete human psychology. New York: Routledge.

Roth, W.-M. (2016b). The primacy of the social and sociogenesis. Integrative Psychological and Behavioral Science, 50(1), 122-141.

Sackur, C., \& Drouhard, J. P. (1997). Algebraic expressions and equations: an example of the evolution of the notions. In E. Pehkonen (Ed.), Proceedings of the 21st Conference of the International Group for the Psychology of Mathematics Education (Vol. 4, pp. 112-119). Lahti: University of Helsinki.

Schindler, M. (2014). Auf dem Weg zum Begriff der negativen Zahlen: Empirische Studie zur Ordnungsrelation für ganze Zahlen aus inferentieller Perspektive. [On the way to the concept of negative number. An empirical study on order relations for integers from an inferential point of view.] Wiesbaden, Germany: Springer Spektrum.

Selter, C., \& Spiegel, H. (1997). Wie Kinder rechnen [how children do arithmetic]. Leipzig: Klett.

Sfard, A. (2008). Thinking as communicating. Human development, the growth of discourses, and mathematizing. Cambridge: Cambridge University Press.

Stephan, M., \& Akyuz, D. (2012). A proposed instructional theory for integer addition and subtraction. Journal for Research in Mathematics Education, 43(4), 428-464.

Tsang, J. M., Blair, K. P., Bofferding, L., \& Schwartz, D. L. (2015). Learning to "see” less than nothing: putting perceptual skills to work for learning numerical structure. Cognition and Instruction, 33(2), 154-197.

Vlassis, J. (2008). The role of mathematical symbols in the development of number conceptualization: The case of the minus sign. Philosophical Psychology, 21(4), 555-570.

Vlassis, J. (2004). Making sense of the minus sign or becoming flexible in 'negativity'. Learning and Instruction, 14, 469-484.

Widjaja, W., Stacey, K., \& Steinle, V. (2011). Locating negative decimals in the number line: insights into the thinking of pre-service primary teachers. Journal of Mathematical Behavior, 30, 80-91. 